\title{
Characterization of Surface-Treated NiTi Alloy by Various Electrochemical Techniques in Phosphate-Buffered Saline
}

\author{
Manju Chembath $^{1,2} \cdot$ J. N. Balaraju ${ }^{1} \cdot$ M. Sujata $^{3}$
}

Received: 2 December 2017 / Revised: 6 March 2018 / Accepted: 7 March 2018 / Published online: 15 March 2018

(c) Springer International Publishing AG, part of Springer Nature 2018

\begin{abstract}
Sol-gel titania thin film coating was prepared on NiTi surfaces, modified with acidified ferric chloride solution. Nanogrids formed on chemical treatment were uniformly covered with titania coating. Cyclic voltammetry studies in phosphate-buffered saline solution revealed that sol-gel titania-coated surface displayed electrochemical properties which were similar to those observed for pure titanium. During polarization, the passive layer formed on modified NiTi was stable for potentials greater than $0.9 \mathrm{~V}$. The overall resistance measured by electrochemical impedance spectroscopy for sol-gel titania surface was in the order of $10^{5} \Omega$, which was approximately two orders higher than bare NiTi surface. The current noise analyzed using electrochemical noise measurements was minimum after sol-gel coating, which emphasizes the better protection power of the surface from the attack of corrosive species. Dynamic impedance studies carried out on bare and titania-coated NiTi also supports the results obtained from cyclic polarization.
\end{abstract}

Keywords Chemical treatment $\cdot$ Sol-gel titania $\cdot$ Voltammetry $\cdot$ Polarization $\cdot$ Noise resistance $\cdot$ Apatite growth

\section{Introduction}

There are several challenging issues in developing an implant material with requisite biological and mechanical properties for biomedical applications. The primary criterion for a biomaterial lies in its ability to exhibit good biocompatibility with a minimal amount of corrosion in the body environment. It is known that implant surfaces in the body will degrade over time due to the dissolution of individual metals [1-5]. However, the rate of metal dissolution can be controlled by modifying the surface and consequently the service life of the implant can be extended with minimal or negligible disturbance to the patient. Thus, surface modification is often a recommended practice to improve

J. N. Balaraju

jnbalraj@nal.res.in

1 Surface Engineering Division, CSIR National Aerospace Laboratories, Post Bag No. 1779, Bangalore, Karnataka 560017, India

2 Department of Chemistry, National Institute of Technology, Calicut, Kerala, India

3 Materials Science Division, CSIR National Aerospace Laboratories, Post Bag No. 1779, Bangalore, Karnataka 560017, India the biocompatibility and corrosion resistance of implant materials.

Compared to conventional coating techniques such as chemical vapor deposition, physical vapor deposition and plasma spraying, sol-gel coating process is less expensive. In a sol-gel process, the nucleation and growth of particles can be controlled, and the desired thickness can be achieved by controlling the dipping cycles. Further, by tailoring the post-annealing conditions, the size and shape of particles in the coating can be varied to achieve the expected properties. Among the various alloys being used for biomedical applications, equiatomic NiTi alloy has found wide applicability because of the shape memory and superelastic property. Several studies on sol-gel-derived titania coatings proved to be efficient in improving the corrosion resistance of NiTi alloys [6-8]. One of the drawbacks of sol-gel coatings, however, is the tendency to undergo de-lamination due to the weak interface between the coating and the base material [9]. To overcome this difficulty, recent trends were aimed at developing sol-gel coatings on a porous or an undulated surface, thus enabling the coating to penetrate and interlock with the base material $[7,10]$. One such study by Tao et al. [7] involved the formation of a corrosion protective titania film on NiTi alloy by employing $\mathrm{NaOH}-\mathrm{HCl}$ pretreatment before sol-gel coating. The pretreatment process was carried 
out for $36 \mathrm{~h}$ to obtain the desired surface roughness that contributed to the better adhesion of titania coating with NiTi alloy. In a similar study, to obtain porous NiTi surface for sol-gel coating, Zhang et al. [10] used ammonium bicarbonate as a temporary space holder in green NiTi disk. On a titanium substrate, the rough surface for sol-gel coating was obtained after micro-arc oxidation treatment, and the combined process resulted in the enhancement of corrosion protection [11]. According to the study, homogeneity of the surface after sol-gel coating compared to micro-arc oxidized surface is the factor that promoted good corrosion resistance.

The pretreatment processes cited in the literature to obtain porous and rough surface are complex, expensive and time-consuming. In an earlier study by the present authors, the morphology of NiTi surface was altered by adopting a chemical treatment using ferric chloride solution to obtain a nanogrid surface [12]. In the present study, to enhance the bioactivity, a barrier coating of sol-gel titania is applied on chemically modified NiTi. The nanostructured NiTi surface formed after chemical treatment is aimed at improving the integrity and adhesion of sol-gel coating onto the surface. Even though numerous studies on sol-gel coatings on NiTi alloy were reported $[6-8,13,14]$, thorough electrochemical understanding of the modified surface has not been described. In the present investigation, the nature of sol-gel titania coatings is characterized using various electrochemical techniques such as cyclic voltammetry, cyclic potentiodynamic polarization and electrochemical noise measurements. It has been reported that after implantation, the potential of the metallics may change in actual body environment. In order to account for the above, dynamic electrochemical impedance measurements were carried out by analyzing the variation of impedance of the coating with respect to potentials.

\section{Materials and Methods}

Hot-rolled NiTi specimens (50.9 at\% nickel) of $10 \mathrm{~mm} \times 10 \mathrm{~mm} \times 1 \mathrm{~mm}$ size were employed in this study. Prior to sol-gel coating, the morphology of the sample surface was modified by chemical treatment in a 3\% acidified ferric chloride solution, the details of which are presented in an earlier study [12].

\subsection{Sol-Gel Coating}

To apply the sol-gel thin film, titanium (IV) isopropoxide (TTIP) (Alfa Aesar 95\%) was used as the precursor. The solution for titania coating was prepared by adding TTIP dropwise to a mixture of isopropanol and acetic acid at room temperature where the molar ratio of alcohol to alkoxide was 50:1. The solution was stirred continuously to obtain a transparent sol. The sol was coated on the prepared chemically treated NiTi samples by dip coating method. The samples were immersed in titania sol and withdrawn at a speed of $6 \mathrm{~cm} / \mathrm{min}$. Multilayered coatings were prepared by repeating the above procedure. Subsequently, annealing at $400{ }^{\circ} \mathrm{C}$ for 5 min was carried out to produce titania film on NiTi alloy.

\subsection{Surface Characterization and Electrochemical Studies}

The morphology of chemically treated and sol-gel-coated samples was studied using Scanning Electron microscopy (Carl Zeiss, Supra 40 VP).

Electrochemical tests were conducted using Autolab PGSTAT302 N. Cyclic voltammetry studies were carried out in the potential range of -1 to $3 \mathrm{~V}$, at a scan rate of $100 \mathrm{mV} / \mathrm{s}$. Cyclic potentiodynamic polarization studies were carried out in phosphate-buffered saline (PBS) physiological solution at $37^{\circ} \mathrm{C}$, at a $\mathrm{pH}$ of 7.3. The sample, platinum strip and saturated calomel electrode were used as working, counter and the reference electrode, respectively. Scan rate for potentiodynamic polarization measurement was $1 \mathrm{mV} / \mathrm{s}$. Electrochemical impedance spectroscopy (EIS) measurements were taken at open-circuit potential. The spectra were acquired in the range $10 \mathrm{mHz}-100 \mathrm{kHz}$. Electrochemical noise measurements were also carried out using two identical working electrodes for selected samples. Current noise relates to the current variations between two identical working electrodes, connected through a zero resistance ammeter (ZRA) and potential noise relates to the variation in potential between coupled working electrode and reference electrode. The variation of potential and current with respect to time was analyzed for a duration of $512 \mathrm{~s}$, and the noise resistance was calculated from the ratio of standard deviation in potential and current fluctuations. The time domain curves were then converted to the frequency domain using fast Fourier transform (FFT) analysis and the corresponding power spectral densities (PSD) were generated. All the experiments were repeated three times for confirming the reproducibility of the results. Dynamic impedance measurement was taken in selected range of frequencies to analyze the variation of impedance with potentials.

\section{Results and Discussion}

\subsection{Surface Analysis}

Surface morphology of chemically treated and sol-gelcoated samples is given in Fig. 1. In the chemically treated condition, the surface exhibited a nanogrid structure comprising one- and two-dimensional channels (Fig. 1a). The dimension of the grid ranged between $50-100 \mathrm{~nm}$, and the inter-grid spacing is around $1 \mu \mathrm{m}$ (Fig. 1b). Figure 1c reveals 

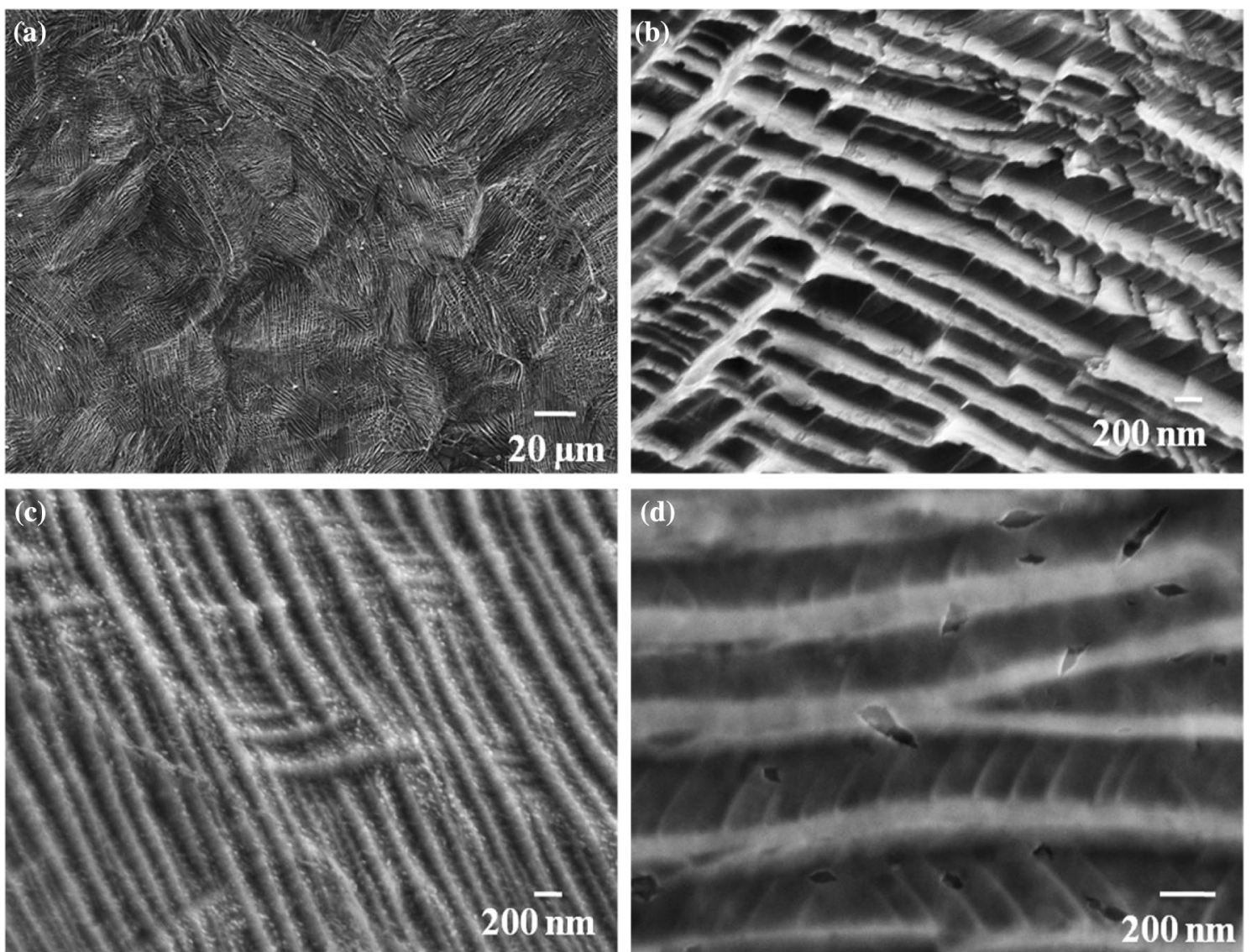

Fig. 1 Surface morphology of NiTi after different treatments $(\mathbf{a}, \mathbf{b})$ chemically treated NiTi- low and high magnification and $\mathbf{c}, \mathbf{d}$ sol-gel titania coating on chemically treated NiTi before and after annealing

the morphology of the surface after sol-gel coating before annealing. The undulations between the grids are covered with titania, and the coating is almost uniform over the surface. Annealing treatment resulted in the formation of more compact titania layer (Fig. 1d) with a minor amount of cracks at some locations. Peel-off tests carried out as per ASTM D3359-09 confirmed that sol-gel titania coating is well adherent to NiTi surface with 4B rating (Fig. 2).
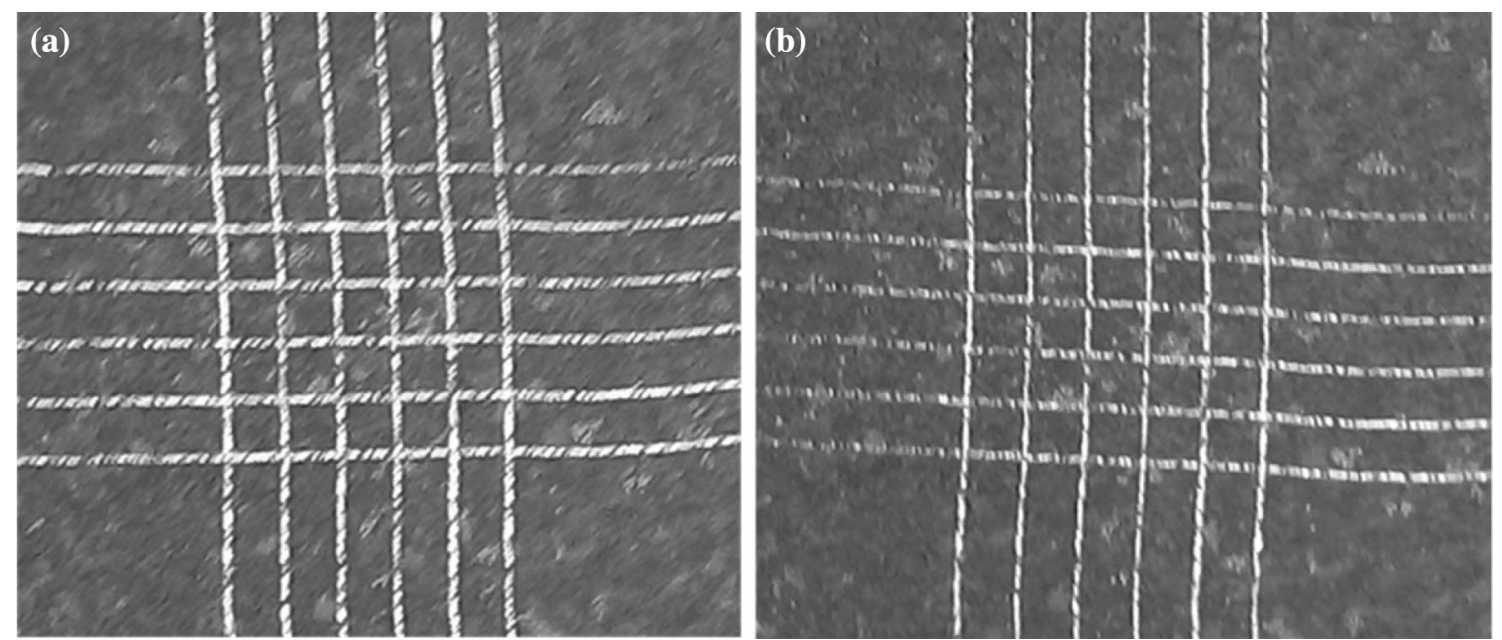

Fig. 2 Photographic images of sol-gel titania-coated NiTi surface $\mathbf{a}$ before and $\mathbf{b}$ after peel-off test 


\subsection{Electrochemical Behavior}

Cyclic voltammetric (CV) curves obtained for bare NiTi, pure titanium (CP Ti), chemically treated NiTi and sol-gel titania samples in the scan range of -1 to $3 \mathrm{~V}$ are given in Fig. 3. From the curve obtained for bare NiTi sample, an increase in the anodic current is noticed once the potential reaches approximately $1.5 \mathrm{~V}$ (Fig. 3a1). This peak can be assigned to the conversion of nickel from 0 to +2 oxidation state, followed by its dissolution [15]. The voltammetric behavior of chemically treated sample is similar to that of untreated $\mathrm{NiTi}$ (Fig. 3a2), but the maximum current attained is $0.039 \mathrm{~A} / \mathrm{cm}^{2}$, whereas in the previous case it is $0.07 \mathrm{~A} /$ $\mathrm{cm}^{2}$. This reduction in current might be due to a marginal enrichment of titanium at the surface after chemical treatment. It should be noted that the dissolution characteristics of NiTi alloy are not altered by chemical treatment.

Figure $3 \mathrm{~b}$ compares the $\mathrm{CV}$ curve obtained for $\mathrm{CP}$ Ti substrate (Fig. $3 b$ (3 and 4)) and sol-gel titania-coated surface (Fig. 3b5) in the same potential range. The cyclic voltammogram for CP Ti during the first cycle is given in Fig. $3 \mathrm{~b} 3$. The initial shallow peak observed at $0.3 \mathrm{~V}$ signifies the conversion to $\mathrm{Ti}^{3+}$ state (Eqs. 1, 2). On increasing the potential, the current remain stable which may be due to the thickening of titania layer. At $1.2 \mathrm{~V}$, the conversion of Ti from $3^{+}$ to $4^{+}$initiates and the current increases until it reaches a peak potential of $2.3 \mathrm{~V}$ (Eq. 3). The slight decrease in current after $2.3 \mathrm{~V}$ signifies the thickening of oxide layer [16]. The oxide layer formed during the process of anodization will prevent the dissolution of titanium. Along with anodic oxidation of titanium, oxidation of water will also occur at a potential of $2.3 \mathrm{~V}$ (Eq. 4) [17]. The various reactions occurring during this process are given below.

$$
\begin{aligned}
& 2 \mathrm{TiO}+\mathrm{H}_{2} \mathrm{O} \rightarrow \mathrm{Ti}_{2} \mathrm{O}_{3}+2 \mathrm{H}^{+}+2 \mathrm{e}^{-} \\
& 2 \mathrm{Ti}+3 \mathrm{H}_{2} \mathrm{O} \rightarrow \mathrm{Ti}_{2} \mathrm{O}_{3}+6 \mathrm{H}^{+}+6 \mathrm{e}^{-} \\
& \mathrm{Ti}_{2} \mathrm{O}_{3}+\mathrm{H}_{2} \mathrm{O} \rightarrow 2 \mathrm{TiO}_{2}+2 \mathrm{H}^{+}+2 \mathrm{e}^{-}
\end{aligned}
$$

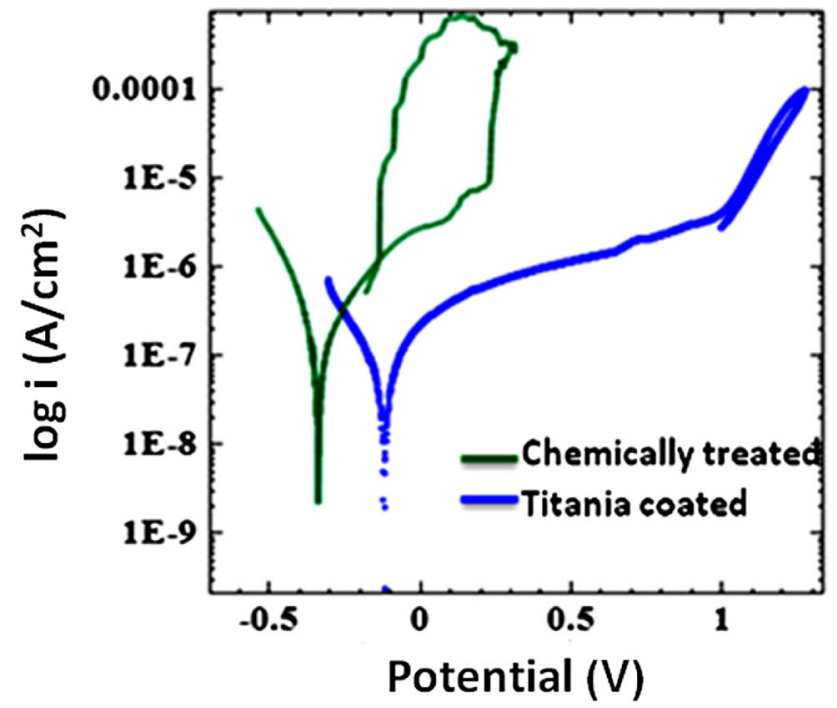

Fig. 4 Potentiodynamic polarization curves obtained for chemically treated and sol-gel-coated samples

$2 \mathrm{H}_{2} \mathrm{O} \rightarrow \mathrm{O}_{2}+4 \mathrm{H}^{+}+4 \mathrm{e}^{-}$

The current observed for $\mathrm{CP} \mathrm{Ti}$ and sol-gel-coated $\mathrm{NiTi}$ are two orders lesser than that observed for bare and chemically treated NiTi. For CP Ti, during the second run, no oxidation peak could be observed, probably due to the complete conversion of titanium to $\mathrm{Ti}^{4+}$ state at the surface (Fig. 3b4). The voltammogram of sol-gel coating is similar to that observed for $\mathrm{CP} \mathrm{Ti}$, in fact, the current started increasing at around $1.5 \mathrm{~V}$, which is observed for bare and chemically treated NiTi alloy. As evident from Fig. 3b5, the maximum current reached for sol-gel-coated NiTi is closer to that obtained for CP Ti (2nd cycle). Therefore, the surface behavior of the sol-gel-coated titania is similar to that of pure titanium.

Cyclic potentiodynamic polarization curves obtained for chemically treated, and sol-gel-coated samples in PBS solution at $37{ }^{\circ} \mathrm{C}$ are given in Fig. 4. There is approximately
Fig. 3 Cyclic voltammograms obtained for the modified NiTi surfaces
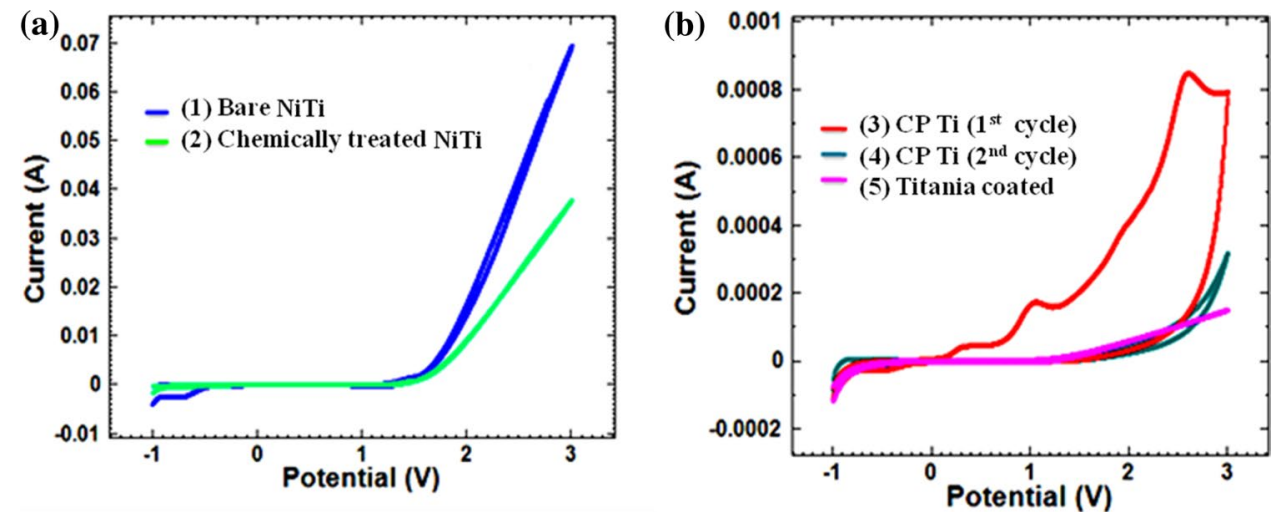
$20 \mathrm{mV}$ shift toward anodic side for bare NiTi [12] and sol-gel-coated NiTi (corrosion potential $-0.18 \mathrm{~V}$ ) when compared to chemically treated surface. The corrosion current density obtained for the sol-gel-coated sample is $7.2 \times 10^{-8} \mathrm{~A} / \mathrm{cm}^{2}$ which is one order less than the value obtained for chemically treated and bare NiTi. During anodic polarization, the chemically treated surface exhibited poor passivity as indicated by the sudden rise in current density at $0.08 \mathrm{~V}$. For bare NiTi, the passive layer is stable until $0.45 \mathrm{~V}$ beyond which it is prone to pitting corrosion [12]. In the case of sol-gel-coated samples, a well-defined passive region which is stable up to $0.96 \mathrm{~V}$ is observed. The potential difference between $E_{\text {corr }}$ and $E_{\mathrm{b}}$ gives the resistance of the surface for pitting corrosion [18]. Results obtained in the present study shows that $\left(E_{\mathrm{b}}-E_{\text {corr }}\right)$ value obtained for sol-gel titania surface is $0.69 \mathrm{~V}$ higher than for chemically treated surface. Hence, pitting resistance has improved due to sol-gel coating. For chemically treated sample, on reversing the scan, the protection potential is $0.23 \mathrm{~V}$ less than the breakdown potential. It is also evident that the surface exhibited sufficient positive hysteresis which signifies the corrosion of the exposed surface during polarization. In the case of sol-gel-coated sample, the surface showed negative hysteresis which conveys that the material attained its passivity at the vertex potential. The enhanced corrosion protection observed on the sol-gel-coated NiTi can be understood from the formation of stable $\mathrm{TiO}_{2}$ layer over the grid structure.
From the analysis of spontaneous fluctuations of electrical parameters by electrochemical noise measurement, the efficiency of protective coatings and the mechanism of corrosion can be understood. Figure 5a represents the oscillation of current with respect to time. The causes for current noise could be various electrochemical processes such as adsorption/desorption of ions at the metal/solution interface, pitting and ionic movement through pores [19]. The current fluctuations observed for the chemically treated sample is relatively high when compared to sol-gel-coated surface. The high current noise observed on chemically treated sample can be due to the severe attack of corrosive ions. Sol-gel titania-coated surface exhibited lower current noise which highlights its ability to protect the surface from the attack of chloride ions. The reduction in the electrochemical noise can be attributed to the better protection performance of the coating [20]. After sol-gel coating, the surface became homogenous and displayed improvement in the impedance and hence the current fluctuations were minimum during the measured interval of time. From the standard deviation of potential and current, noise resistance is calculated. The noise resistance calculated from the time domain spectra is found to be $3.3 \times 10^{4}$ and $7.8 \times 10^{5} \Omega$ for chemically treated and sol-gel-coated NiTi, respectively. For bare NiTi, the noise resistance measured is $5.7 \times 10^{3} \Omega$. The time domain spectra are converted into the frequency domain by FFT to generate power spectral density (PSD) plots. PSD plots are
Fig. 5 a Current noise measurements for the samples under study and electrochemical noise analysis of $\mathbf{b}$ bare NiTi $\mathbf{c}$ chemically treated and d sol-gelcoated samples
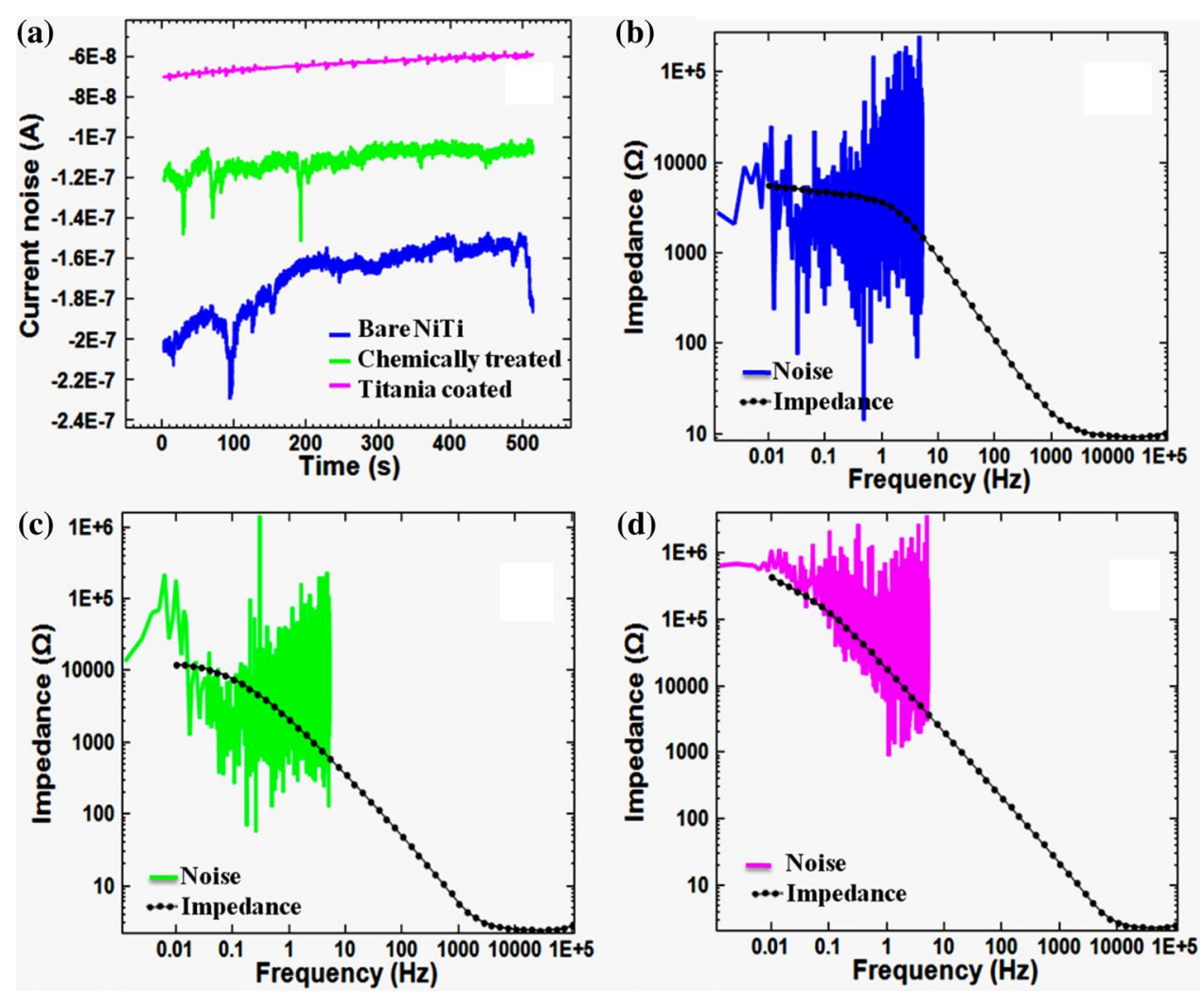
then superimposed on Bode modulus plots to compare the accuracy of the measurement (Fig. 5b-d). It can be clearly observed from the figure that at $0.01 \mathrm{~Hz}$, the resistance measured using PSD and Bode plots are almost comparable. The slight mismatch or variation in resistance measured can be attributed to the fact that an impedance spectrum is generated using external ac excitation source, whereas in electrochemical noise analysis the measurements are made without any external perturbation. Both EIS and ENM techniques show that the corrosion protection of bare and chemically treated surfaces is inferior compared to sol-gel-coated NiTi samples. Thus, titania sol-gel thin film increased the corrosion protection of chemically treated NiTi alloy and the impedance measured is two order higher than bare NiTi.

Dynamic impedance measurements were carried out for bare NiTi in the potential range from ocp $(-0.5 \mathrm{~V})$ to the pitting potential $(0.5 \mathrm{~V})$, and the results obtained in the form of Nyquist plot-3D are shown in Fig. 6a. It is evident from the figure that as potential increases from ocp to higher, the impedance also increased. But as soon as the potential reaches $0.4 \mathrm{~V}$, the data show scattered values which is due to the corrosion of the active surface [21]. The results are in consistent with the potentiodynamic polarization data obtained for bare NiTi [12].

Bode plots are generated at open-circuit potential $(-0.5 \mathrm{~V})$ and in the passive region $(0.3 \mathrm{~V})$. The results obtained after fitting with appropriate equivalent circuit are shown in Fig. $6 \mathrm{~b}$ and Table 1. At rest potential, the surface shows single time constant behavior and the equivalent circuit used for fitting the measured data is $\mathrm{R}(\mathrm{QR})$. The breakdown of the oxide film on bare NiTi is in the range of $0.3-0.6 \mathrm{~V}[22,23]$. The impedance attained its maximum at
$0.3 \mathrm{~V}$ and the Bode plots (Fig. 6b) are fitted with two time constant circuit $R(Q[R(Q R)])$. It is evident from the figure that at the passive region, bare NiTi shows highest impedance. During anodic polarization, the NiTi surface forms an oxide layer whose thickness increases with increase in potential [24]. This is reflected in the lowering of capacitance value in the passive region. The $n_{\mathrm{p}}$ value signifies the extent of stability of the porous oxide layer formed during polarization. The deviation of $n_{p}$ value from unity and lower capacitance confirms that even though the thickness of the oxide layer is higher at the passive region, it lacks the protectiveness. The surface of a bare NiTi is non-uniform and hence, the oxide layer formed on polarizing the surface is defective [25]. This might be the reason for the sudden pitting of bare NiTi surface, at still higher potential $(0.4 \mathrm{~V})$.

Dynamic impedance studies were carried out on sol-gelcoated NiTi surface, and the obtained Nyquist plot is shown in Fig. 7a. It is evident from the figure that impedance increases with increase in potential, reaches maximum impedance at $0.4 \mathrm{~V}$, beyond which it decreases. Higher impedance can be accounted to the defect-free oxide layer. However, the discharge of oxygen from NiTi surface dominates at still higher potentials and the impedance decreases.

Bode plots were obtained at rest potential $(-0.2 \mathrm{~V})$, passive region $(0.4 \mathrm{~V})$ and oxygen evolution regions $(1.2 \mathrm{~V})$ for the sol-gel-coated NiTi surface (Fig. 7b). The plots were fitted with appropriate equivalent circuit and are given in Table 2. At ocp and in the passive region, the surface shows two layer structure which is fitted with the equivalent circuit $\mathrm{R}(\mathrm{Q}[\mathrm{R}(\mathrm{QR})])$. The impedance measured at $-0.4 \mathrm{~V}$ is approximately double than at the rest potential. There is a slight decrease in the capacitance value on moving from ocp
Fig. 6 a Nyquist plot-3D and b Bode plots obtained at different potentials for bare NiTi alloy
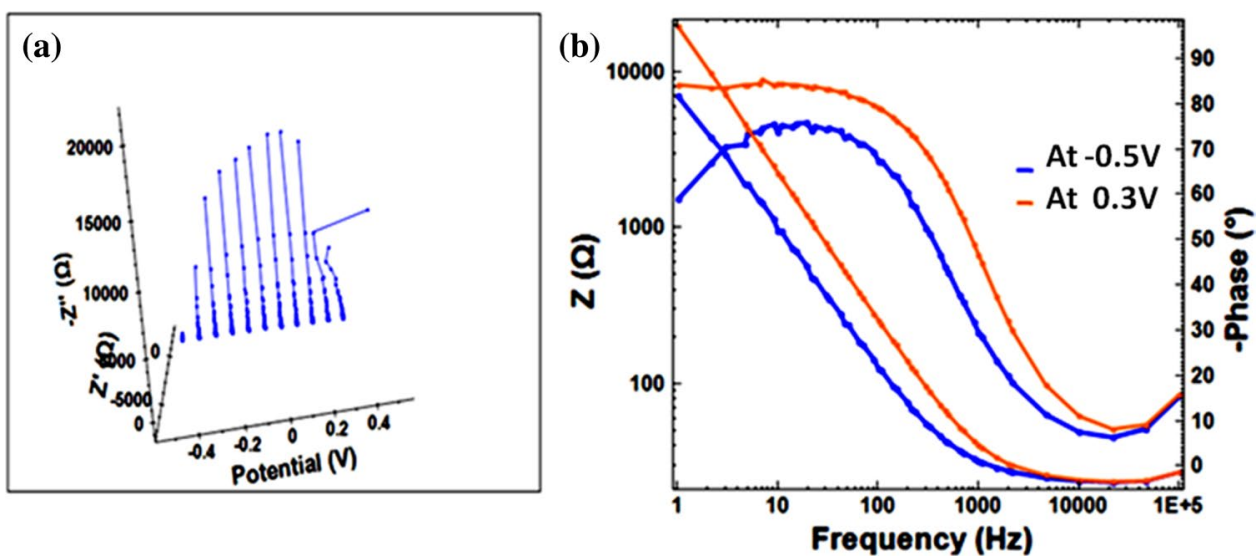

Table 1 EIS parameters obtained after fitting the data for bare NiTi alloy

\begin{tabular}{llcccccc}
\hline Potential (V) & Circuit & $Q_{\mathrm{p}}\left(\mathrm{Ss}^{\mathrm{n}} \mathrm{cm}^{-2}\right)$ & $n_{\mathrm{p}}$ & $R_{\mathrm{p}}\left(\Omega \mathrm{cm}^{2}\right)$ & $Q_{\mathrm{b}}\left(\mathrm{Ss}^{\mathrm{n}} \mathrm{cm}^{-2}\right)$ & $n_{\mathrm{b}}$ & $R_{\mathrm{b}}\left(\Omega \mathrm{cm}^{2}\right)$ \\
\hline-0.5 & $\mathrm{R}(\mathrm{QR})$ & - & - & - & $2.3 \times 10^{-5}$ & 0.91 & 8110 \\
0.3 & $\mathrm{R}(\mathrm{Q}[\mathrm{R}(\mathrm{QR})])$ & $9.0 \times 10^{-6}$ & 0.84 & $4.0 \times 10^{4}$ & $1.0 \times 10^{-7}$ & 0.94 & $1.9 \times 10^{5}$ \\
\hline
\end{tabular}


Fig. 7 a Nyquist plot-3D and $\mathbf{b}$ Bode plots obtained at different potentials for sol-gel-coated NiTi alloy
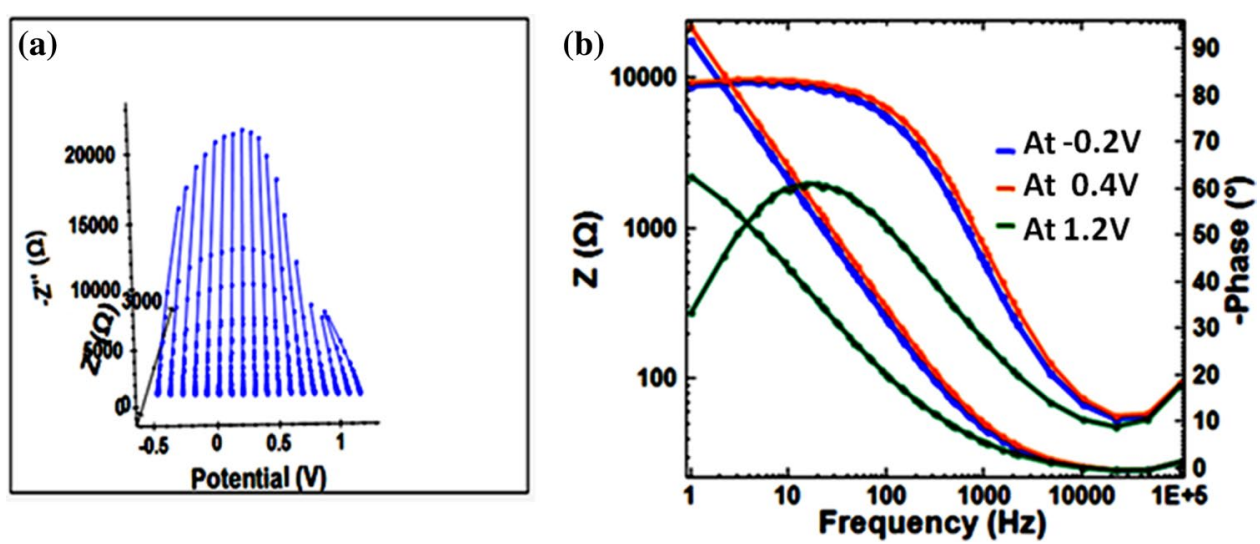

Table 2 EIS parameters obtained after fitting the data for sol-gel titania-coated NiTi alloy

\begin{tabular}{llllllll}
\hline Potential $(\mathrm{V})$ & Circuit & $Q_{\mathrm{p}}\left(\mathrm{Ss}^{\mathrm{n}} \mathrm{cm}^{-2}\right)$ & $n_{\mathrm{p}}$ & $R_{\mathrm{p}}\left(\Omega \mathrm{cm}^{2}\right)$ & $Q_{\mathrm{b}}\left(\mathrm{Ss}^{\mathrm{n}} \mathrm{cm}^{-2}\right)$ & $n_{\mathrm{b}}$ & $R_{\mathrm{b}}\left(\Omega \mathrm{cm}^{2}\right)$ \\
\hline At -0.2 & $\mathrm{R}(\mathrm{Q}[\mathrm{R}(\mathrm{QR})])$ & $7.2 \times 10^{-6}$ & 0.93 & $3.4 \times 10^{4}$ & $4.1 \times 10^{-6}$ & 0.92 & $5.0 \times 10^{5}$ \\
At 0.4 & $\mathrm{R}(\mathrm{Q}[\mathrm{R}(\mathrm{QR})])$ & $4.4 \times 10^{-6}$ & 0.89 & $5.7 \times 10^{4}$ & $2.6 \times 10^{-6}$ & 0.81 & $9.3 \times 10^{5}$ \\
At 1.2 & $\mathrm{R}(\mathrm{QR})$ & & & & $8.0 \times 10^{-5}$ & 0.75 & $6.8 \times 10^{4}$ \\
\hline
\end{tabular}

to higher, which can be attributed to the thickening of the passive layer. The phase angle measured at ocp and at the passive region are the same $\left(-83^{\circ}\right)$. Along with anodic oxidation of NiTi surface, oxidation of water proceeds simultaneously. Beyond $0.4 \mathrm{~V}$, oxygen evolution reaction initiates because of which, the impedance decreases with potential. At $1.2 \mathrm{~V}$, the surface shows single layer structure with lower impedance. The phase angle dropped to $-63^{\circ}$ and the capacitive behavior decreases. This is due to the high rate of oxygen evolution process which dominates under highly polarized condition. The passivity of the surface is still higher as evident from the negative hysteresis loop formation for the sol-gel-coated NiTi surface.

\section{Conclusions}

Titania coating was successfully developed on chemically treated NiTi alloy by sol-gel process. The electrochemical behavior of sol-gel-coated NiTi surface was similar to that of pure titanium. The passive layer formed on the surface was stable until $0.96 \mathrm{~V}$ and displayed good corrosion resistance than chemically treated or bare NiTi. This confirms the improvement in pitting resistance of NiTi surface due to sol-gel titania coating. Electrochemical noise analysis revealed that the fluctuations in current observed were least for titania-coated surface, and there was two order improvement in the impedance values than bare NiTi. There was a good correlation for the impedance data measured by dynamic impedance and electrochemical noise measurements.
Acknowledgements The authors would like to thank the Director, CSIR-NAL, Council of Scientific and Industrial Research (CSIR), New Delhi, for giving permission to publish this work. The authors also thank Head, SED, Dr. S.K. Bhaumik and his group and Mr. Siju for the help they have extended for various characterizations. One of the authors (Manju Chembath) acknowledges the financial assistance received from CSIR in the form of senior research fellowship.

\section{References}

1. Hallab N, Jacobs JJ, Black J (2000) Hypersensitivity to Metallic biomaterials: a review of leukocyte migration inhibition assays. Biomaterials 21:1301-1314

2. Lalor PA, Revell PA, Gray AB, Wright S, Railton GT, Freeman MA (1991) Sensitivity to titanium: a cause of implant failure? Bone Joint J 73:25-28

3. Zhang D, Zeng W, Zi Z, Chu PK (2009) Corrosion resistance of TiN coated biomedical nitinol under deformation. Mater Sci Eng C29:1599-1603

4. Scales JT (1956) Internal prostheses. J Bone Joint Surg Br 38:754-761

5. Mirjalili M, Momeni M, Ebrahimi N, Moayed MH (2013) Comparative study on corrosion behaviour of Nitinol and stainless steel orthodontic wires in simulated saliva solution in presence of fluoride ions. Mater Sci Eng C33:2084-2093

6. Liu JX, Yang DZ, Shi F, Cai YJ (2003) Sol-gel deposited TiO film on NiTi surgical alloy for biocompatibility improvement. Thin Solid Films 429:225-230

7. Fu T, Wu X, Wu F, Luo M, Dong B, Ji Y (2012) Surface modification of NiTi alloy by sol-gel derived porous $\mathrm{TiO}_{2}$ film. Trans Nonferrous Met Soc China 22:1661-1666

8. Fu T, Shen Y, Alajmi Z, Wang Y, Yang S, Li G (2014) Sol-gel derived Ag-containing $\mathrm{TiO}_{2}$ films on surface roughened biomedical NiTi alloy. Ceram Int 40:12423-12429

9. Maitz MF (2009) Surface modification of Ti-Ni alloys for biomedical applications. In: Yoneyama T, Miyazaki S (eds) Shape 
memory alloys for biomedical applications. CRC Press, Boca Raton, pp 173-193

10. Zhang JX, Guan RF, Zhang XP (2011) Synthesis and characterization of sol-gel hydroxyapatite coatings deposited on porous NiTi alloys. J Alloy Compd 509:4643-4648

11. Aliofkhazraei M, Sabour Rouhaghdam A, Laleh M, Shanaghi A (2010) Enhancement of corrosion protection of micro-arc oxidation by applying nanostructured $\mathrm{TiO}_{2}$ thin film via the "sol-gel" method. Anti-Corros Methods Mater 57:75-82

12. Chembath M, Balaraju JN, Sujata M (2015) Surface characteristics, corrosion and bioactivity of chemically treated biomedical grade NiTi alloy. Mater Sci Eng C 56:417-425

13. Ahn YU, Kim EJ, Kim HT, Hahn SH (2003) Variation of structural and optical properties of sol-gel $\mathrm{TiO}_{2}$ thin films with catalyst concentration and calcination temperature. Mater Lett 57:4660-4666

14. Chiu KY, Wong MH, Cheng FT, Man HC (2007) Characterization and corrosion studies of titania-coated NiTi prepared by sol-gel technique and steam crystallization. Appl Surf Sci 253:6762-6768

15. Abdallah M, El-Etre AY (2003) Corrosion inhibition of nickel in sulfuric acid using tween surfactants. Port Electrochim Acta 21:315-326

16. Liu Z, Liu X, Donatus U, Thompson GE, Skeldon P (2014) Corrosion behaviour of the anodic oxide film on commercially pure titanium in $\mathrm{NaCl}$ environment. Int J Electrochem Sci 9:3558-3573

17. Simka W (2011) Preliminary investigations on the anodic oxidation of $\mathrm{Ti}-13 \mathrm{Nb}-13 \mathrm{Zr}$ alloy in a solution containing calcium and phosphorus. Electrochim Acta 56:9831-9837

18. Standard test method for conducting cyclic potentiodynamic polarization measurements to determine the Corrosion Susceptibility of Small Implant Devices. ASTM F2129-08
19. Groysman A (2010) Corrosion for everybody. Springer, New York

20. Hirozawa T, Turcotte DE (1993) Electrochemical impedance: analysis and interpretation. In: Scully JR, Silverman DC, Kendig MW (eds) Use of electrochemical noise in the study of inhibitor systems: part I-the effect of silicate polymerization on the inhibition of aluminum. ASTM STP 1188 American Society for Testing and Materials, Philadelphia, pp 205-219

21. Wang J, Li N, Han E, Ke W (2006) Effect of pH, temperature and $\mathrm{Cl}^{-}$concentration on electrochemical behavior of NiTi shape memory alloy in artificial saliva. J Mater Sci Mater Med 17:885-890

22. Pound BG (2008) The electrochemical behavior of nitinol in simulated physiological solutions. J Biomed Mater Res A 85:1103-1113

23. Tabrizian M, Thierry B, Savadago O, Yahia LH (1999) Surface characterization of sterilized electropolished NiTi shape memory alloy as biomaterials. In: Proceedings of SPIE conference on sensory phenomena and measurement instrumentation for smart structures and materials, vol 3670, pp 106-114

24. Luo P, Wang S, Zhao T, Li Y (2013) Surface characteristics, corrosion behavior, and antibacterial property of Ag-implanted NiTi alloy. Rare Met 32:113-121

25. Venkateswarlu K, Rameshbabu N, Sreekanth D, Bose AC, Muthupandi V, Subramanian S (2013) Fabrication and characterization of micro-arc oxidized fluoride containing titania films on $\mathrm{Cp}$ Ti. Ceram Int 39:801-812 